Applied Remote Sensing

\title{
Errata: Soil moisture derived using two apparent thermal inertia functions over Canterbury, New Zealand
}

Mammatt Sohrabinia Wolfgang Rack

Peyman Zawar-Reza 


\title{
Errata: Soil moisture derived using two apparent thermal inertia functions over Canterbury, New Zealand
}

\author{
Mammatt Sohrabinia, ${ }^{\text {a,c }}$ Wolfgang Rack, ${ }^{\text {b }}$ and Peyman Zawar-Reza ${ }^{a}$ \\ ${ }^{a}$ University of Canterbury, Centre for Atmospheric Research, \\ Department of Geography, Ilam, Christchurch 8140, New Zealand \\ bUniversity of Canterbury, Centre for Antarctic Studies and Research, \\ Gateway Antarctica, Ilam, Christchurch 8140, New Zealand \\ ${ }^{c}$ Ministry for Primary Industries, Spatial, Forestry \& Land Management, \\ 25 The Terrace (Pastoral House), Wellington 6011, New Zealand
}

[DOI: 10.1117/1.JRS.8.089999]

The pdf version of this article [J. Appl. Remote Sens. 8(1), 083624 (May 22, 2014)] contained several errors that interfered with the intended meaning of soil moisture values. In the abstract, "ME $\approx-15 \times \mathrm{m}^{3} \cdot \mathrm{m}^{-3}$ volumetric $\mathrm{SM}$ " should appear as "ME $\approx-15 \mathrm{~m}^{3} \cdot \mathrm{m}^{-3}$ volumetric SM," and "ME $\approx-20 \times \mathrm{m}^{3} \cdot \mathrm{m}^{-3}$ " should appear as "ME $\approx-20 \mathrm{~m}^{3} \cdot \mathrm{m}^{-3}$." In the first full paragraph on Page $14, " \sim 5 \mathrm{~m}^{3} \cdot \mathrm{m}^{-3} \times$ volumetric $\times \mathrm{SM}$ " should appear as “ $5 \mathrm{~m}^{3} \cdot \mathrm{m}^{-3}$ volumetric SM." The pdf version of the article was corrected on 23 May 2014. 